\title{
Development of a Risk Scoring System for Predicting Anastomotic Leakage Following Laparoscopic Rectal Cancer Surgery
}

This article was published in the following Dove Press journal:

Therapeutics and Clinical Risk Management

\author{
Zhongbo $\mathrm{Han}^{1, *}$ \\ Dawei Chen ${ }^{2} * *$ \\ Yan $\mathrm{Li}^{3}$ \\ Guangshuai Zhou ${ }^{3}$ \\ Meng Wang' \\ Chao Zhang $\mathbb{D}^{\prime}$ \\ 'Department of Gastrointestinal Surgery, \\ Zibo Central Hospital, Shandong \\ University, Zibo, Shandong, People's \\ Republic of China; ${ }^{2}$ Department of \\ General Surgery, Jiangyin People's \\ Hospital, School of Medicine, Southeast \\ University, Jiangyin, Jiangsu, People's \\ Republic of China; ${ }^{3}$ Department of \\ Quality and Safety Management, Zibo \\ Central Hospital, Shandong University, \\ Zibo, Shandong, People's Republic of \\ China
}

*These authors contributed equally to this work

\begin{abstract}
Purpose: To develop a risk scoring system that can predict the incidence of anastomotic leakage after laparoscopic rectal cancer surgery.

Patients and Methods: The clinical data of 387 patients with rectal cancer who underwent laparoscopic low anterior resection were retrospectively collected. Univariable and multivariable logistic regression analyses were used to evaluate independent risk factors for postoperative anastomotic leakage. A simplified points system was then developed based on the corresponding regression coefficient $\beta$ of each risk factor. Receiver operating characteristic (ROC) analysis was used to evaluate the performance and the optimal cut-off value in predicting anastomotic leakage. The performance of the points system was then externally validated in an independent cohort of 192 patients based in another institution.

Results: Anastomotic leakage occurred in 36 of 387 patients with rectal cancer $(9.30 \%)$. Logistic multivariable regression analysis showed that males, maximum tumor diameter ( $\geq 5 \mathrm{~cm}$ ), operation time ( $\geq 180 \mathrm{~min}$ ), preoperative chemoradiation, intraoperative blood transfusion and the anastomosis level from the anal verge $(\leq 5 \mathrm{~cm})$ were independent risk factors for the incidence of anastomotic leakage. According to the scoring standard, the risk points of each patient were calculated. ROC analysis based on the risk points showed that the area under the curve (AUC) was 0.795 (95\% CI:0.752-0.834) and the optimal cut-off value was 6 , yielding a sensitivity of $88.89 \%$ and a specificity of $62.96 \%$. Using this risk points system, the AUC of another cohort of 192 patients from another institution who underwent laparoscopic low anterior resection for rectal cancer was 0.853 (95\% CI:0.794-0.900, p<0.001) and patients with risk points $\geq 6$ had a $21.05 \%$ chance of developing anastomotic leakage.

Conclusion: This risk points system for predicting anastomotic leakage following laparoscopic rectal cancer surgery may be useful for surgeons in their decisions to perform intraoperative diversion stoma, which can reduce the incidence of postoperative anastomotic leakage.
\end{abstract}

Keywords: anastomotic leakage, rectal cancer, laparoscopic surgery, risk score

\section{Introduction}

Rectal cancer is one of the most common malignant tumors of the digestive tract. Current evidence suggests that laparoscopic radical resection of rectal cancer has similar long-term oncological outcomes compared with conventional open surgery and is the most widely recommended surgical strategy for the management of rectal cancer. $^{1-3}$ Anastomotic leakage after low anterior resection is a common and severe complication during the management of rectal cancer. ${ }^{4}$ It leads to increased
Department of Gastrointestinal Surgery,

Zibo Central Hospital, Shandong

University, 54 West Gongqingtuan Road,

Zibo, 255000, Shandong, People's

Republic of China

Tel +8605333570671

Fax +8605333570672

Email zhangchao2020202I@163.com
Therapeutics and Clinical Risk Management 2021:17 |45-153 
hospitalization costs and delays in postoperative adjuvant chemotherapy, which may affect the treatment efficacy and subsequently lead to a decline in long-term survival. ${ }^{5-7}$ For patients with a high risk of anastomotic leakage, intraoperative diversion stoma can reduce the incidence of postoperative anastomotic leakage. ${ }^{8,9}$ Therefore, the need to accurately predict the risk of anastomotic leakage and minimize the creation of unnecessary diversion stomas is of great clinical significance.

Several studies have been published on risk factors for anastomotic leakage following rectal cancer surgery, but the results are inconsistent. ${ }^{10-13}$ Frequently reported risk factors include low rectal anastomosis, preoperative radiotherapy and male gender. ${ }^{14,15}$ Other risk factors reported to be related to anastomotic leakage are body mass index (BMI), American Society of Anesthesiologists (ASA) score, tumor size, longer operative time, intra-operative blood transfusions/loss, number of stapler firings and tumor stage, among others. ${ }^{14,15}$ A possible explanation for the lack of consensus on potential risk factors for anastomotic leakage among studies might be the heterogeneous nature of several factors related to the studies. These could include study designs, population, methods and analysis. To assess potential preoperative risk factors, observational cohort designs are the best choice instead of randomized controlled trials (RCTs). In a meta-analysis, Pommergaard and colleagues demonstrated that anastomotic leakage had a multifactorial origin. ${ }^{14}$ We hypothesize that all the risk factors mentioned above influence the risk of anastomotic leakage, but the degrees of impact may vary. Using these potential risk factors for anastomotic leakage to guide the decision-making in whether to create a diversion stoma or not during surgery represents a challenging practical problem. ${ }^{16}$ In 2009, Dulk designed and proposed a standardized postoperative leakage scoring system (Dutch leakage score) for the early diagnosis of anastomotic leakage. ${ }^{17}$ The variables included in the Dutch Leakage score can easily be obtained during history taking and physical examination. An assessment of the score showed a significant difference in leakage-score between patients with and without anastomotic leakage. The Dutch leakage scoring system was the driver for developing a risk scoring system for predicting anastomotic leakage.

In this study, we aimed to develop a quantitative risk points system for predicting anastomotic leakage by using preoperative and intraoperative data of patients as potential risk factors. These risk factors were the significant risk factors influencing anastomotic leakage and included the clinical and inherent tumor characteristics of the patient before and during the operation. ${ }^{18}$ Based on these risk factors, surgeons would be able to decide on whether to perform a diversion stoma during the surgery. This risk points scoring system was developed to predict the risk of anastomotic leakage and provide a reference comparison for decision-making during the operation. Furthermore, this system could assist in avoiding the use of anastomosis in patients at very high risk of leakage, thus minimizing the use of aids for fecal incontinence and defecation frequency. ${ }^{19}$

\section{Patients and Methods}

\section{Patients}

The clinical data of 387 patients with rectal cancer who underwent laparoscopic low anterior rectal resection in the Department of Gastrointestinal Surgery of Zibo Central Hospital, Shandong University, from January 2015 to December 2019 were retrospectively analyzed. The inclusion criteria were as follows: preoperatively diagnosed as rectal cancer by colonoscopy and biopsy pathology; newly diagnosed patients with rectal cancer; the lower edge of the tumor was 3-12 cm from the anal verge; no operative contraindications were confirmed by preoperative multidisciplinary consultation and discussion and laparoscopic low anterior rectal resection was successfully performed without conversion to laparotomy. Patient exclusion criteria were: (i) those with local organ invasion and distant metastasis by MRI and enhanced CT before operation; (ii) patients with multiple colon tumors; (iii) patients who underwent Miles or Hartmann surgery and (iv) patients with intraoperative diversion stoma. Using the same inclusion/exclusion criteria, the clinical data of another cohort of 192 patients who underwent laparoscopic low anterior resection for rectal cancer in Jiangyin people's Hospital, School of Medicine, Southeast University, from January 2015 to December 2019 were also collected. The Ethics Committee of Zibo Central Hospital, Shandong University and Jiangyin People's Hospital, School of Medicine, Southeast University approved the study. Written informed consent was obtained from all patients.

\section{Surgical Procedures}

Conventional five ports laparoscopic surgery for rectal cancer was performed according to the technique described previously. ${ }^{20}$ The surgical procedures strictly followed the TME and standard oncologic practices: 
adequate distal margin, ligation at the origin of the arterial supply for the involved rectal segment and mesorectal excision. To ensure a tension-free anastomosis, vascular ligation occurred either at the takeoff of the inferior mesenteric artery from the aorta or just distal to the takeoff of the left colic artery. Then, end-to-end colorectal anastomosis was performed with a circular stapler and the air leak test was confirmed to be negative. The same group of surgeons performed all surgical operations.

\section{Diagnosis of Anastomotic Leakage}

The definition of anastomotic leakage after anterior resection for rectal cancer is in line with the International Study Group of Rectal Cancer: ie, a communication between the intra- and extraluminal compartments owing to a defect of the integrity of the intestinal wall at the anastomosis between the colon and rectum/anus. ${ }^{21}$ Anastomotic leakage was diagnosed when any of the following conditions occurred: sudden increase in the pelvic drainage tube, combined with turbid or fecal/purulent content; persistent fever with signs of peritonitis or pelvic abscess; radiographic contrast enema or CT with transrectal instillation of contrast revealing leakage of the contrast agent and palpable anastomotic defect on digital rectal examination.

\section{Statistical Analysis}

Continuous data (age, BMI, preoperative albumin, ASA score, NRS score, maximum tumor diameter, operation time, intraoperative hemorrhage and anastomosis level from the anal verge) were expressed as mean $\pm \mathrm{SD}$ and compared between groups using two-tailed Student's $t$-test. Categorical data (gender, smoking status, preoperative clinical AJCC stage, preoperative chemoradiation and intraoperative blood transfusion) were analyzed using a chi-square test or Fisher's exact probability test. Only the risk factors with a p-value less than 0.20 in the univariable logistic regression analysis were selected for input into the multivariable model. Based on the method proposed by Sullivan, each statistically significant factor in the multivariable logistic regression analysis was assigned point according to the corresponding regression coefficient $\beta^{22}$ Specifically, $0<\beta<1$, assigned 1 point; $\beta>1$, assigned 2 points; $\beta>2$, assigned 3 points; and $\beta>3$, assigned 4 points. The risk score of each patient was calculated as the sum of the risk factor points. A ROC analysis was conducted according to the risk score points of each patient. The area under the curve (AUC) and optimal cut-off value were calculated. In ROC analysis, AUC values of 0.7-0.8 were considered acceptable, $0.8-0.9$ as excellent, and those above 0.9 as outstanding. ${ }^{23}$ Using anastomotic leakage as the classification variable, the optimal cut-off value for risk score points was obtained by applying Youden's index (sensitivity + specificity - 1), choosing AUC values where the index was maximal. Using this risk points system, the ROC analysis of an external validation cohort of 192 patients who underwent laparoscopic low anterior resection for rectal cancer was conducted and the AUC value was calculated. SPSS26.0 (SPSS Inc., Chicago, IL) was used for statistical analysis. MedCalc ${ }^{\circledR}$ Statistical Software version 19.5.6 (MedCalc software Ltd, Ostend, Belgium) was used for ROC analysis. $\mathrm{P}<0.05$ was considered to be statistically significant.

\section{Results}

\section{Univariate and Multivariate Logistic Regression Analysis for Anastomotic Leakage After Laparoscopic Rectal \\ Cancer Surgery}

The preoperative and intraoperative clinical data of 387 patients with rectal cancer are summarized in Table 1. The number of patients who developed anastomotic leakage was $36 / 387(9.3 \%)$. Of the 36,29 cases were successfully managed by continuous negative pressure irrigation and drainage by a modified double-lumen irrigation-suction tube ${ }^{24} 7$ cases were successfully managed with temporary diversion loop stoma (transverse colostomy or terminal ileostomy) combined with continuous negative pressure irrigation and drainage. Following univariable logistic regression, potential risk factors were selected for the multivariable analysis (Table 1). Multivariable logistic regression confirmed that male gender, preoperative chemoradiation, maximum tumor diameter, operation time, intraoperative blood transfusion and anastomosis level from the anal verge to be independent risk factors for anastomotic leakage after laparoscopic rectal cancer surgery (Table 1 ). The regression coefficient $(\beta)$ of each statistically significant risk factor is reported in Table 1.

\section{Establishment of a Simple Risk Scoring System and ROC Analysis Based on Patients' Risk Scores}

Based on the regression coefficient ( $\beta$ ) of each statistically significant risk factor in the multivariable logistic regression analysis, the risk score points of each patient were calculated. The risk score of each patient ranged from $0-13$ points. ROC analysis based on the risk score points showed that the AUC was 0.795 (95\% CI:0.752-0.834) 
Table I The Clinical Data of 387 Patients with Rectal Cancer Who Underwent Laparoscopic Low Anterior Resection for Rectal Cancer

\begin{tabular}{|c|c|c|c|c|c|c|c|c|}
\hline \multirow[t]{2}{*}{ Parameters } & & \multirow[t]{2}{*}{ No. of AL/Total } & \multicolumn{2}{|c|}{ Univariate Analysis } & \multicolumn{4}{|c|}{ Multivariate Analysis } \\
\hline & & & HR & $\mathbf{p}$ & HR & $\beta$ & $95 \% \mathrm{Cl}$ & $\mathbf{p}$ \\
\hline Gender & $\begin{array}{l}\text { Male } \\
\text { Female }\end{array}$ & $\begin{array}{l}29 / 243 \text { (11.9\%) } \\
7 / 144 \text { (4.9\%) }\end{array}$ & 2.652 & 0.025 & 20.682 & 3.029 & $3.938-108.621$ & $<0.001$ \\
\hline Age & $\begin{array}{l}<70 \\
\geq 70\end{array}$ & $\begin{array}{l}24 / 273(8.8) \\
12 / 114(10.5 \%)\end{array}$ & 1.059 & 0.879 & & & & \\
\hline BMI & $\begin{array}{l}<25 \\
\geq 25\end{array}$ & $\begin{array}{l}28 / 33(8.5 \%) \\
8 / 56(14.29 \%)\end{array}$ & 1.761 & 0.188 & & & & 0.810 \\
\hline Smoke & $\begin{array}{l}\text { Yes } \\
\text { No }\end{array}$ & $\begin{array}{l}21 / 208(10.1 \%) \\
15 / 179(8.4 \%)\end{array}$ & 1.228 & 0.563 & & & & \\
\hline Preoperative albumin $(\mathrm{g} / \mathrm{dL})$ & $\begin{array}{l}<3.5 \\
\geq 3.5\end{array}$ & $\begin{array}{l}8 / 105(7.6 \%) \\
28 / 282(9.9 \%)\end{array}$ & 1.036 & 0.927 & & & & \\
\hline ASA Score & $\begin{array}{l}1-2 \\
3\end{array}$ & $\begin{array}{l}32 / 352(9.1 \%) \\
4 / 35 \text { (11.4\%) }\end{array}$ & 1.290 & 0.651 & & & & \\
\hline NRS Score & $\begin{array}{l}<3 \\
\geq 3\end{array}$ & $\begin{array}{l}29 / 324(8.9 \%) \\
7 / 63 \text { (II.1\%) }\end{array}$ & 1.272 & 0.590 & & & & \\
\hline Preoperative clinical AJCC stage & $\begin{array}{l}\text { I+II } \\
\text { III }\end{array}$ & $\begin{array}{l}14 / 228(6.1 \%) \\
22 / 159(13.8 \%)\end{array}$ & 2.445 & 0.012 & & & & 0.288 \\
\hline Preoperative chemoradiation & $\begin{array}{l}\text { Yes } \\
\text { No }\end{array}$ & $\begin{array}{l}13 / 64(20.3 \%) \\
23 / 323(7.1 \%)\end{array}$ & 3.325 & 0.002 & 8.629 & 2.155 & $2.205-33.769$ & 0.002 \\
\hline Maximum tumor diameter & $\begin{array}{l}>5 \mathrm{~cm} \\
\leq 5 \mathrm{~cm}\end{array}$ & $\begin{array}{l}20 / 133(15.0 \%) \\
16 / 254(6.3 \%)\end{array}$ & 2.633 & 0.006 & 2.211 & 0.793 & $1.00 \mathrm{I}-4.834$ & 0.047 \\
\hline Operation time & $\begin{array}{l}<180 \mathrm{~min} \\
\geq 180 \mathrm{~min}\end{array}$ & $\begin{array}{l}|6 / 24|(6.6 \%) \\
20 / \mid 46(\mid 3.7 \%)\end{array}$ & 2.178 & 0.028 & 2.612 & 0.960 & $1.194-5.716$ & 0.016 \\
\hline Intraoperative hemorrhage & $\begin{array}{l}<150 \mathrm{~mL} \\
\geq 150 \mathrm{~mL}\end{array}$ & $\begin{array}{l}25 / 3 \mid 4(7.9 \%) \\
11 / 73(15.1 \%)\end{array}$ & 2.051 & 0.064 & & & & \\
\hline Intraoperative blood transfusion & $\begin{array}{l}\text { Yes } \\
\text { No }\end{array}$ & $\begin{array}{l}12 / 77(15.6 \%) \\
24 / 310(7.7 \%)\end{array}$ & 2.200 & 0.038 & 3.984 & 1.382 & $1.009-15.732$ & 0.049 \\
\hline Anastomosis level from anal verge & $\begin{array}{l}\leq 5 \mathrm{~cm} \\
>5 \mathrm{~cm}\end{array}$ & $\begin{array}{l}26 / 153(17 \%) \\
10 / 234(4.3 \%)\end{array}$ & 3.960 & $<0.001$ & 3.393 & 1.222 & $1.517-7.586$ & 0.003 \\
\hline
\end{tabular}

Abbreviations: AL, anastomotic leakage; BMI, body mass index; ASA, American Society of Anesthesiologists; NRS, nutrition risk screening; AJCC, American Joint Committee on Cancer.

with an optimal cut-off value of 6 , yielding a sensitivity of $88.89 \%$ and a specificity of $62.96 \%$, as shown in Figure 1.

Evaluation of the Performance of the Risk Scoring System for Predicting Anastomotic Leakage

Based on the cut-off value of the risk score points in the ROC analysis, 387 patients with rectal cancer were divided into two groups ( $\geq 6$ and $<6$ ). Of 159 patients with a risk score points $\geq$ 6, $29(18.24 \%)$ developed postoperative anastomotic leakage.
Only 7 patients (3.07\%) of 228 patients with risk score points $<6$ developed postoperative anastomotic leakage (Figure 2). The incidences of anastomotic leakage due to other risk factors are listed in Table 1. We also used ROC analysis to compare the diagnostic performance of a risk score with three continuous variables (maximum tumor diameter, operation time and anastomosis level from the anal verge). As shown in Figure 3, the AUC and the diagnostic accuracy of the risk scoring system were significantly greater than that of the three continuous variables. 


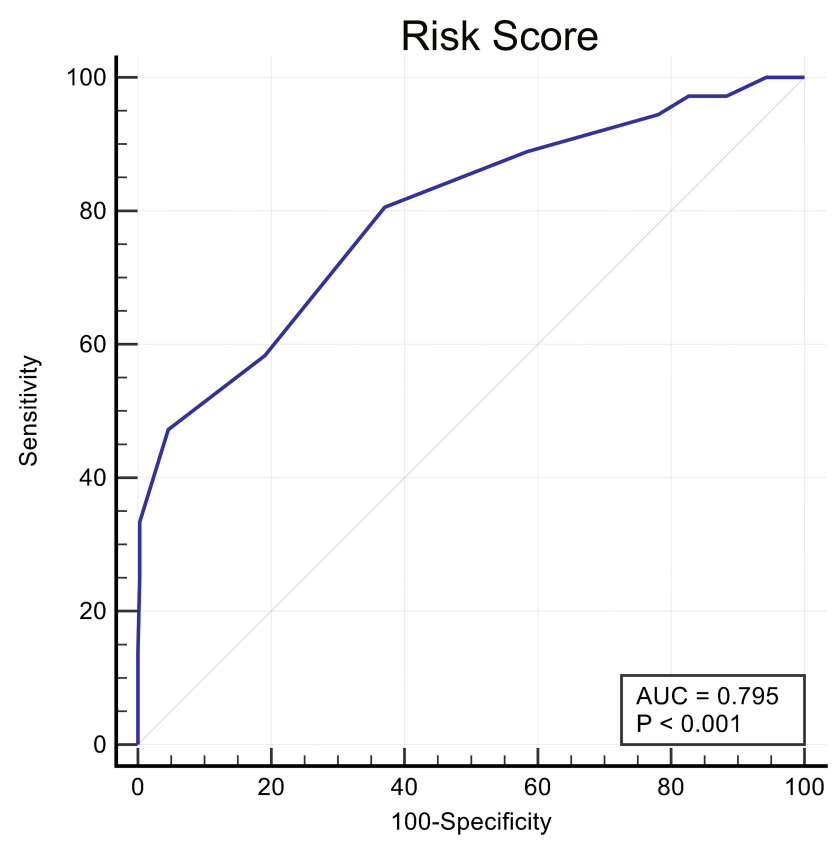

Figure I ROC curve based on the risk points. The area under the curve (AUC) was 0.795 (95\% Cl:0.752-0.834) and the optimal cut-off value was 6.

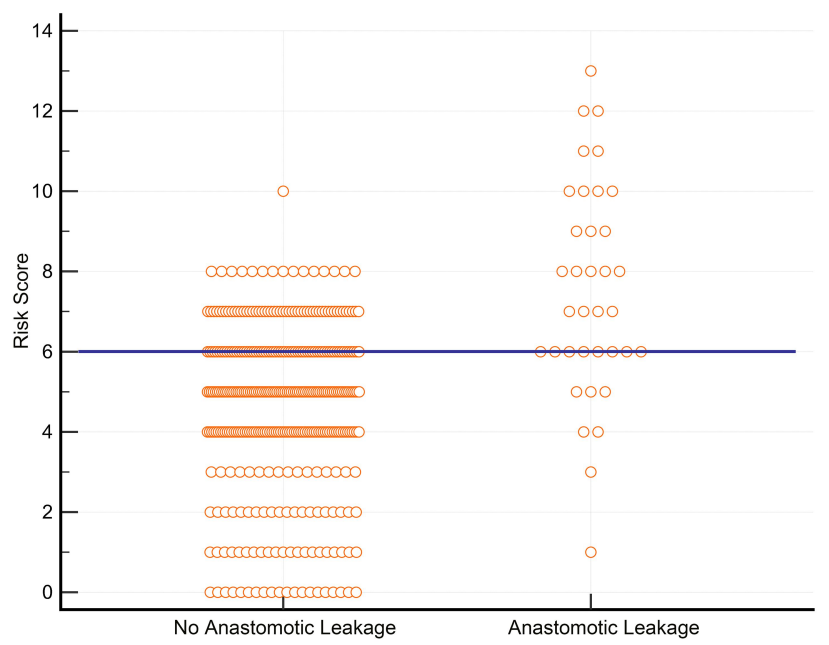

Figure 2 The distribution of patients according to the high or low risk score. 387 patients with rectal cancer were divided into two groups $(\geq 6$ and $<6$ ).

\section{Validation of the Risk Scoring System for Predicting Anastomotic Leakage}

To independently validate the performance of the risk score in predicting anastomotic leakage, we collected the clinical data of 192 patients with rectal cancer who underwent laparoscopic low anterior resection for rectal cancer in Jiangyin people's Hospital, School of Medicine, Southeast University, as shown in Table 2. There were no differences in the case-mix between the training and

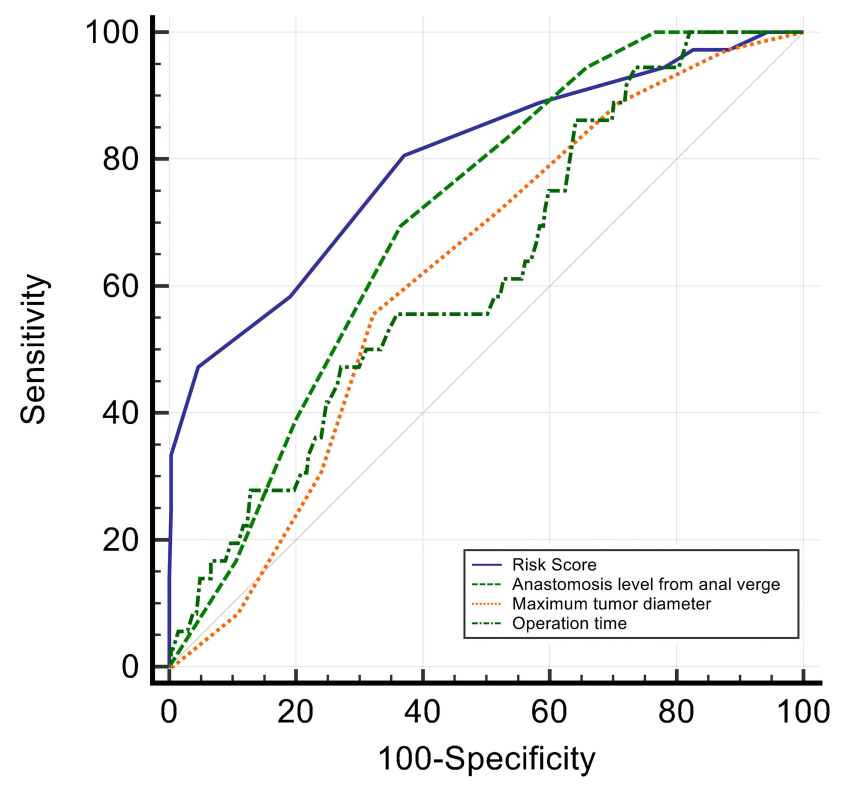

Figure 3 Comparison of the risk score system with the three continuous variables (maximum tumor diameter, operation time and anastomosis level from anal verge). For risk score system, $\mathrm{AUC}=0.795$ (95\% Cl:0.752-0.834); For maximum tumor diameter, AUC $=0.621$ (95\% Cl:0.570-0.669); For operation time, AUC $=0.624$ (95\% $\mathrm{Cl}: 0.573-0.672)$; For anastomosis level from anal verge, AUC $=0.703 \quad(95 \%$ Cl:0.655-0.748).

validation sets (Table S1). The number of patients who developed anastomotic leakage was 23/192 (11.98\%). There were 95 patients with risk score points $\geq 6$ and 20 $(21.05 \%)$ of them had developed postoperative anastomotic leakage. Whereas only 3 patients (3.09\%) out of 97 patients with risk score points $<6$ had developed postoperative anastomotic leakage (Figure 4A). As shown in Figure 4B, the AUC of the risk scoring system for the 192 patients by ROC analysis was 0.853 (95\% CI:0.794-0.900, $\mathrm{p}<0.001)$. Therefore, the validity of the risk score in predicting anastomotic leakage is reliable and stable.

\section{Discussion}

Anastomotic leakage is a serious complication following low anterior resection for rectal cancer. The occurrence of anastomotic leakage not only increases the length of hospital stay and medical costs, but also causes further delays in the adjuvant treatment of patients after surgery, thereby affecting the overall survival rate of patients. ${ }^{15,25,26}$ Anastomotic leakage is a complication that represents a real challenge for rectal cancer surgeons. Although there have been innovations in laparoscopic surgical techniques in recent years, the incidence of anastomotic leakage has been reported to range between $9.3 \%$ and $13 \%{ }^{9,27,28}$ The temporary diverting stoma has proved to 
Table 2 The Clinical Data of 192 Patients with Rectal Cancer Who Underwent Laparoscopic Low Anterior Resection for Rectal Cancer from Another Center

\begin{tabular}{|c|c|c|c|}
\hline Parameters & & AL/Total & $P$ value \\
\hline Gender & $\begin{array}{l}\text { Male } \\
\text { Female }\end{array}$ & $\begin{array}{l}19 / 122(15.6 \%) \\
4 / 70(5.7 \%)\end{array}$ & 0.043 \\
\hline Age & $\begin{array}{l}<70 \\
\geq 70\end{array}$ & $\begin{array}{l}15 / 125(12.0 \%) \\
8 / 67 \text { (11.9\%) }\end{array}$ & 0.990 \\
\hline BMI & $\begin{array}{l}<25 \\
\geq 25\end{array}$ & $\begin{array}{l}17 / 155(10.9 \%) \\
6 / 37(16.2 \%)\end{array}$ & 0.377 \\
\hline Smoke & $\begin{array}{l}\text { Yes } \\
\text { No }\end{array}$ & $\begin{array}{l}13 / 108 \text { (12.0\%) } \\
10 / 84(11.9 \%)\end{array}$ & 0.978 \\
\hline Preoperative albumin ( $g / d \mathrm{~L}$ ) & $\begin{array}{l}<3.5 \\
\geq 3.5\end{array}$ & $\begin{array}{l}8 / 59(13.6 \%) \\
15 / 133(11.3 \%)\end{array}$ & 0.653 \\
\hline ASA Score & $\begin{array}{l}1-2 \\
3\end{array}$ & $\begin{array}{l}20 / 17 \mid(11.7 \%) \\
3 / 21 \text { (14.3\%) }\end{array}$ & 0.722 \\
\hline NRS Score & $\begin{array}{l}<3 \\
\geq 3\end{array}$ & $\begin{array}{l}18 / 152(11.8 \%) \\
5 / 40(12.5 \%)\end{array}$ & 0.909 \\
\hline Preoperative clinical AJCC stage & $\begin{array}{l}\text { I+II } \\
\text { III }\end{array}$ & $\begin{array}{l}12 / 110(10.9 \%) \\
11 / 82(13.4 \%)\end{array}$ & 0.597 \\
\hline Preoperative chemoradiation & $\begin{array}{l}\text { Yes } \\
\text { No }\end{array}$ & $\begin{array}{l}10 / 43(23.3 \%) \\
13 / 149(8.7 \%)\end{array}$ & 0.010 \\
\hline Maximum tumor diameter & $\begin{array}{l}>5 \mathrm{~cm} \\
\leq 5 \mathrm{~cm}\end{array}$ & $\begin{array}{l}11 / 68(16.2 \%) \\
12 / 124(9.7 \%)\end{array}$ & 0.185 \\
\hline Operation time & $\begin{array}{l}<180 \mathrm{~min} \\
\geq 180 \mathrm{~min}\end{array}$ & $\begin{array}{l}10 / 114(8.8 \%) \\
13 / 78(16.7 \%)\end{array}$ & 0.098 \\
\hline Intraoperative hemorrhage & $\begin{array}{l}<150 \mathrm{~mL} \\
\geq 150 \mathrm{~mL}\end{array}$ & $\begin{array}{l}12 / 126(9.5 \%) \\
11 / 66(16.7 \%)\end{array}$ & 0.148 \\
\hline Intraoperative blood transfusion & $\begin{array}{l}\text { Yes } \\
\text { No }\end{array}$ & $\begin{array}{l}11 / 65(16.9 \%) \\
12 / 127(9.4 \%)\end{array}$ & 0.131 \\
\hline Anastomosis level from anal verge & $\begin{array}{l}\leq 5 \mathrm{~cm} \\
>5 \mathrm{~cm}\end{array}$ & $\begin{array}{l}16 / 87(18.4 \%) \\
7 / 105(6.7 \%)\end{array}$ & 0.013 \\
\hline
\end{tabular}

Abbreviations: $\mathrm{AL}$, anastomotic leakage; BMI, body mass index; ASA, American Society of Anesthesiologists; NRS, nutrition risk screening; AJCC, American Joint Committee on Cancer.

effectively reduce the incidence of postoperative anastomotic leakage and prevent severe consequences attributed to leakage, such as local recurrence and morbidity. ${ }^{25,29}$

Although the application of diverting stoma reduces the incidence of anastomotic leakage, the complications related to the stoma are also worthy of attention by surgeons. Holmgren reported that in $24 \%$ of patients, the temporary stoma was converted to a permanent stoma and $9 \%$ of patients experienced serious complications after stoma reversal. ${ }^{30}$ The most common reason for a permanent stoma was anastomotic leakage. ${ }^{32}$ Other risk factors such as tumor stage IV and impaired anorectal function have also been reported to influence the conversion to permanent stoma. ${ }^{30,31}$ On the other hand, stomas have a negative psychological impact on patients and increase the costs and challenges associated with home care. Therefore, effective creation of stomas in patients with a high risk of anastomotic leakage before the end of the surgical procedure and avoiding unnecessary diversion stomas are of great importance.

In previous studies, there have been inconsistencies on the role of risk factors for anastomotic leakage after rectal cancer surgery. ${ }^{10-13}$ However, these inconsistencies do not suggest that these potential risk factors do not influence the risk of anastomotic leakage following rectal cancer surgery. There is a possibility that the risk of anastomosis attributed to each of these potential risk factors varies. This makes it difficult for surgeons to accurately assess the risk of anastomotic leakage for patients with more than one risk factor and hence unable to decide on whether to perform a diversion stoma or not. This was the main driver for our attempt at developing a risk scoring system to quantify the risk of anastomotic leakage.

Based on the results of previous studies, we included as many potential risk factors as possible in the model. The intent was to create a risk score that would accurately reflect the risk of postoperative anastomotic leakage. From the results of the ROC analysis, the performance of the scoring system was acceptable The incidence of anastomotic leakage in the low-risk score group was significantly lower than the high-risk score group. To minimize limitations associated with generalizability because of using patients from a single center, we also confirmed the predictive performance of the score in an independent validation cohort from another center. Although we tried to minimize biases as much as possible, there were still some limitations that need to be considered. Our scoring system was based on simple logistic regression. LASSO is a more advanced regression analysis method for variable selection and accurate prediction. ${ }^{32}$ Another limitation was that the risk scores obtained from the logistic regression were not continuous. This weakened the accuracy of this scoring system to some extent. Since this scoring system was based on the Chinese population, whether it is applicable to Western populations still needs to be evaluated. The present study was based on retrospective data and a relatively small sample size. Hence, whether this risk score system will be essential for decision-making in surgical practice still requires confirmation using multi-center prospective studies with large sample sizes. If this scoring 

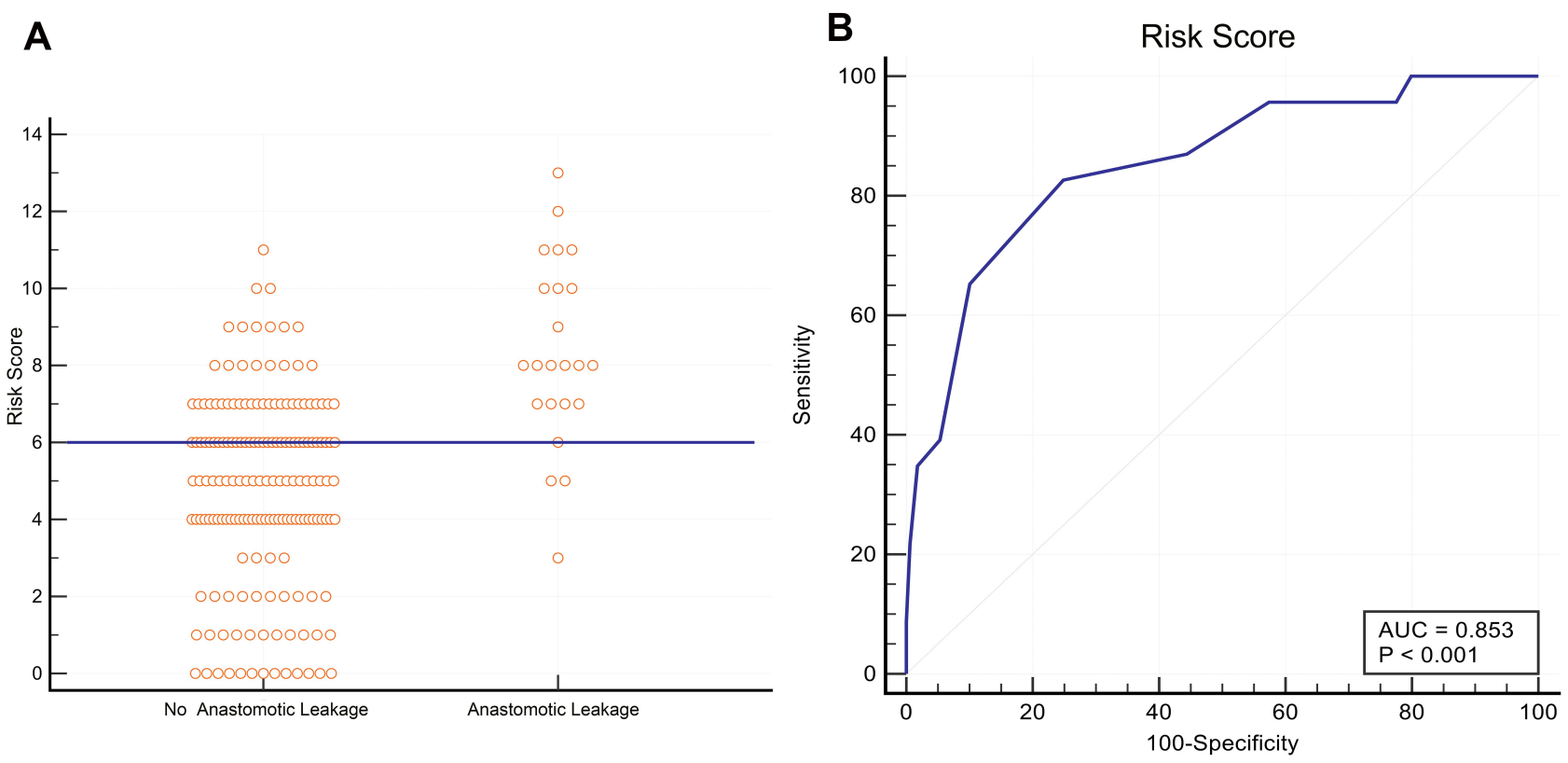

Figure 4 Validation of the risk scoring system for predicting anastomotic leakage. 192 patients with rectal cancer who underwent laparoscopic low anterior resection for rectal cancer from another center were divided into two groups according to the high or low risk score $(\geq 6$ and $<6)$. (A) The distribution of patients according to the high or low risk score. (B) The ROC curve of the risk scoring system for the 192 patients, AUC $=0.853$ ( $95 \%$ Cl:0.794-0.900, $\mathrm{p}<0.00 \mathrm{I}$ ).

system is used in subsequent prospective studies, it is anticipated that the overall incidence of anastomotic leakage and the rates of non-essential stomas will be reduced. If future prospective studies yield promising results, definitive RCTs that randomly allocate patients will be needed.

\section{Conclusion}

In conclusion, our study confirmed that the application of a risk scoring system in predicting the risk of anastomotic leakage was significantly better than the use of a single risk factor. Our findings can provide rectal cancer surgeons with a practical quantitative scoring system to evaluate the risk of anastomotic leakage before the end of the surgical procedure and provide a reference comparison for surgical decision-making.

\section{Data Sharing Statement}

The data that support the results of this study are available from the corresponding author on reasonable request.

\section{Ethics Statement}

This study complied with the principles of the Declaration of Helsinki and was approved by the Ethics Committee of Zibo Central Hospital, Shandong University and Jiangyin people's Hospital, School of Medicine, Southeast
University. Written informed consent was obtained from all patients.

\section{Acknowledgments}

The authors would like to express their gratitude to EditSprings for the expert linguistic services provided.

\section{Author Contributions}

All authors made a significant contribution to the work reported, whether that is in the conception, study design, execution, acquisition of data, analysis and interpretation, or in all these areas; took part in drafting, revising or critically reviewing the article; gave final approval of the version to be published; have agreed on the journal to which the article has been submitted; and agree to be accountable for all aspects of the work. All authors approved the final version of the article and its submission.

\section{Disclosure}

The authors declare that there are no conflicts of interest.

\section{References}

1. Jayne DG, Guillou PJ, Thorpe $\mathrm{H}$, et al. Randomized trial of laparoscopic-assisted resection of colorectal carcinoma: 3-year results of the UK MRC CLASICC Trial Group. J Clin Oncol. 2007;25:3061-3068. doi:10.1200/JCO.2006.09.7758 
2. Fleshman J, Sargent DJ, Green E, et al. Laparoscopic colectomy for cancer is not inferior to open surgery based on 5-year data from the COST Study Group trial. Ann Surg. 2007;246:655-664. doi:10.1097/ SLA.0b013e318155a762

3. Veldkamp R, Kuhry E, Hop WCJ, et al. Laparoscopic surgery versus open surgery for colon cancer: short-term outcomes of a randomised trial. Lancet Oncol. 2005;6:477-484. doi:10.1016/S1470-2045(05) 70221-7

4. Boström P, Haapamäki MM, Rutegård J, et al. Population-based cohort study of the impact on postoperative mortality of anastomotic leakage after anterior resection for rectal cancer. BJS Open. 2018;3:106-111. doi:10.1002/bjs5.50106

5. Lu ZR, Rajendran N, Lynch AC, et al. Anastomotic leaks after restorative resections for rectal cancer compromise cancer outcomes and survival. Dis Colon Rectum. 2016;59:236-244. doi:10.1097/ DCR.0000000000000554

6. Ramphal W, Boeding JR, Gobardhan PD, et al. Oncologic outcome and recurrence rate following anastomotic leakage after curative resection for colorectal cancer. Surg Onco. 2018;27:730-736. doi:10.1016/j.suronc.2018.10.003

7. Wang S, Liu J, Wang S, et al. Adverse effects of anastomotic leakage on local recurrence and survival after curative anterior resection for rectal cancer: a systematic review and meta-analysis. World J Surg. 2017;41:277-284. doi:10.1007/s00268-016-3761-1

8. Matthiessen P, Hallböök O, Ruteg Ard J, et al. Defunctioning stoma reduces symptomatic anastomotic leakage after low anterior resection of the rectum for cancer: a randomized multicenter trial. Ann Surg. 2007;246:207-214. doi:10.1097/SLA.0b013e3180603024

9. Bertelsen C, Andreasen A, Jørgensen T, et al. Anastomotic leakage after anterior resection for rectal cancer: risk factors. Colorectal Dis. 2010;12:37-43. doi:10.1111/j.1463-1318.2008.01711.x

10. Jung SH, Yu CS, Choi PW, et al. Risk factors and oncologic impact of anastomotic leakage after rectal cancer surgery. Dis Colon Rectum. 2008;51:902-908. doi:10.1007/s10350-008-9272-x

11. Eberl T, Jagoditsch M, Klingler A, et al. Risk factors for anastomotic leakage after resection for rectal cancer. Am J Surg. 2008;196:592-598. doi:10.1016/j.amjsurg.2007.10.023

12. Kang CY, Halabi WJ, Chaudhry OO, et al. Risk factors for anastomotic leakage after anterior resection for rectal cancer. JAMA Surg. 2013;148:65-71. doi:10.1001/2013.jamasurg.2

13. Park JS, Choi G-S, Kim SH, et al. Multicenter analysis of risk factors for anastomotic leakage after laparoscopic rectal cancer excision: the Korean laparoscopic colorectal surgery study group. Ann Surg. 2013;257(4):665-671. doi:10.1097/SLA.0b013e31827b8ed9

14. Pommergaard HC, Gessler B, Burcharth J, et al. Preoperative risk factors for anastomotic leakage after resection for colorectal cancer: a systematic review and meta-analysis. Colorectal Dis. 2014;16:662-671. doi:10.1111/codi.12618

15. Qu H, Liu Y, Bi D-S. Clinical risk factors for anastomotic leakage after laparoscopic anterior resection for rectal cancer: a systematic review and meta-analysis. Surg Endosc. 2015;29:3608-3617. doi:10.1007/s00464-015-4117-x

16. Schlesinger NH, Smith H. The effect of a diverting stoma on morbidity and risk of permanent stoma following anastomotic leakage after low anterior resection for rectal cancer: a nationwide cohort study. Int J Colorectal Dis. 2020;1-8. doi:10.1007/s00384-02003625-8

17. Den Dulk M, Noter SL, Hendriks ER, et al. Improved diagnosis and treatment of anastomotic leakage after colorectal surgery. Eur J Surg Oncol. 2009;35:420-426. doi:10.1016/j.ejso.2008.04.009
18. Jestin P, Påhlman L, Gunnarsson U. Risk factors for anastomotic leakage after rectal cancer surgery: a case-control study. Colorectal Dis. 2008;10:715-721. doi:10.1111/j.1463-1318.2007.01466.x

19. Kverneng Hultberg D, Svensson J, Jutesten H, et al. The impact of anastomotic leakage on long-term function after anterior resection for rectal cancer. Dis Colon Rectum. 2020;63:619-628. doi:10.1097/ DCR.0000000000001613

20. Fukunaga Y, Higashino M, Tanimura S, et al. Laparoscopic mesorectal excision with preservation of the pelvic autonomic nerves for rectal cancer. Hepatogastroenterology. 2007;54:85-90.

21. Rahbari NN, Weitz J, Hohenberger W, et al. Definition and grading of anastomotic leakage following anterior resection of the rectum: a proposal by the International Study Group of Rectal Cancer. Surgery. 2010;147:339-351. doi:10.1016/j.surg.2009.10.012

22. Sullivan LM, Massaro JM, D’Agostino RB Sr. Presentation of multivariate data for clinical use: the Framingham Study risk score functions. Stat Med. 2004;23:1631-1660. doi:10.1002/sim.1742

23. Mandrekar JN. Receiver operating characteristic curve in diagnostic test assessment. J Thorac Oncol. 2010;5:1315-1316. doi:10.1097/ JTO.0b013e3181ec173d

24. Li L, Xue B, Yang C, et al. Clinical characteristics of colonoscopic perforation and risk factors for complications after surgical treatment. J Laparoendosc Adv Surg Tech A. 2020;30:1153-1159. doi:10.1089/ lap.2020.0086

25. Den Dulk M, Marijnen C, Collette L, et al. Multicentre analysis of oncological and survival outcomes following anastomotic leakage after rectal cancer surgery. Br J Surg. 2009;96(9):1066-1075. doi:10.1002/bjs.6694

26. Ptok H, Marusch F, Meyer F, et al. Impact of anastomotic leakage on oncological outcome after rectal cancer resection. $\mathrm{Br} J$ Surg. 2007;94:1548-1554. doi:10.1002/bjs.5707

27. Warschkow R, Steffen T, Thierbach J, et al. Risk factors for anastomotic leakage after rectal cancer resection and reconstruction with colorectostomy. A retrospective study with bootstrap analysis. Ann Surg Oncol. 2011;18:2772-2782. doi:10.1245/s10434-011-1696-1

28. Zheng $\mathrm{H}, \mathrm{Wu} \mathrm{Z}, \mathrm{Wu} \mathrm{Y}$, et al. Laparoscopic surgery may decrease the risk of clinical anastomotic leakage and a nomogram to predict anastomotic leakage after anterior resection for rectal cancer. Int J Colorectal Dis. 2019;34:319-328. doi:10.1007/s00384-0183199-z

29. Montedori A, Cirocchi R, Farinella E, et al. Covering ileo- or colostomy in anterior resection for rectal carcinoma. Cochrane Database Syst Rev. 2010;12:CD006878. doi:10.1002/14651858.CD006878.pub2

30. Holmgren K, Kverneng Hultberg D, Haapamaki MM, et al. High stoma prevalence and stoma reversal complications following anterior resection for rectal cancer: a population-based multicentre study. Colorectal Dis. 2017;19:1067-1075. doi:10.1111/codi.13771

31. Gadan S, Floodeen H, Lindgren R, et al. What is the risk of permanent stoma beyond 5 years after low anterior resection for rectal cancer? A 15-year follow-up of a randomized trial. Colorectal Dis. 2020; Online ahead of print. doi:10.1111/codi.15364

32. Yang SU, Park EJ, Baik SH, et al. Modified colon leakage score to predict anastomotic leakage in patients who underwent left-sided colorectal surgery. J Clin Med. 2019;8:1450. doi:10.3390/ jem8091450 


\section{Publish your work in this journal}

Therapeutics and Clinical Risk Management is an international, peerreviewed journal of clinical therapeutics and risk management, focusing on concise rapid reporting of clinical studies in all therapeutic areas, outcomes, safety, and programs for the effective, safe, and sustained use of medicines. This journal is indexed on PubMed Central, CAS,
EMBase, Scopus and the Elsevier Bibliographic databases. The manuscript management system is completely online and includes a very quick and fair peer-review system, which is all easy to use. Visit http://www.dovepress.com/testimonials.php to read real quotes from published authors.

Submit your manuscript here: https://www.dovepress.com/therapeutics-and-clinical-risk-management-journal 